\title{
A modelagem (matemática) implícita nos fazeres de uma modista
}

The (mathematical) modelling implicit in the works of a dressmaker

Zulma Elizabete de Freitas Madruga ${ }^{1}$

\section{Resumo}

Este artigo objetiva fazer uma análise comparativa entre os processos utilizados por uma modista em seus trabalhos profissionais, e os procedimentos de modelagem (matemática). A colaboradora desta pesquisa foi uma profissional do sul do Brasil que trabalha com produção de roupas exclusivas e em larga escala. A mesma concedeu entrevista por meio de narrativas. Como procedimento metodológico, foi utilizado o mapeamento na pesquisa educacional, organizado em dois momentos: apreensão dos dados por meio de narrativas da colaboradora desta pesquisa; e significação dessas informações - identificação, compreensão e análise criteriosa das narrativas da entrevistada. Como resultado, pode-se perceber que a modista, embora não tenha conhecimento sobre emprego da modelagem em seus fazeres, utiliza-se destes procedimentos para elaboração e produção de roupas para suas clientes.

Palavras chave: modelagem matemática; narrativas; processos criativos; modista

\begin{abstract}
This article aims to make a comparative analysis between the processes used by a dressmaker in her professional work, and the procedures of modelling (mathematics). The collaborator of this research was a professional from the south of Brazil who works with exclusive and large scale clothing production. The same granted interview through narratives. As a methodological procedure, mapping was used in educational research, organized in two moments: data apprehension through narratives of the collaborator of this research; and significance of this information - identification, understanding and careful analysis of the interviewee's narratives. As a result, it can be seen that the dressmaker, although she does not have knowledge about the use of modeling in her work, uses these procedures to elaborate and produce clothes for her clients.
\end{abstract}

Keywords: modelling mathematics; narratives; creative processes; dressmaker. 


\section{Introdução}

Ressalta-se nas Diretrizes Curriculares Nacionais da Educação Básica - DNCEB (BRASIL, 2013), a necessidade de proporcionar ao estudante o acesso aos níveis mais elevados do ensino, da pesquisa e da criação artística, de acordo com a capacidade individual. O senso criativo, inerente às pessoas e proveniente, principalmente, de seu patrimônio e contexto humano, social e cultural, necessita de estímulo, e o mais indicado seria estimulá-lo na pessoa enquanto estudante (MADRUGA, 2016). Esse desenvolvimento do senso criativo e incitação para que o estudante expresse sua criatividade deve ser feito desde os anos iniciais da Educação Básica.

De acordo com a Lei de Diretrizes e Bases - LDB (BRASIL, 1996), a educação, desde os anos iniciais do Ensino Fundamental, tem por finalidade, o desenvolvimento do raciocínio e das atividades de expressão do estudante, bem como de sua integração ao meio físico e social e a atividades complementares, como iniciação artística. Tais atividades permitem proporcionar espaços em que os estudantes, em qualquer dos níveis de ensino, tenham a oportunidade, na escola, de desenvolver o senso criativo.

Nos documentos como LDB (BRASIL, 1996), DNCEB (BRASIL, 2013), Parâmetros Curriculares Nacionais - PCN (BRASIL, 1999) e Base Nacional Comum Curricular - BNCC (BRASIL, 2017), identificam-se orientações aos professores para a adoção de procedimentos pedagógicos que propiciem aos estudantes a compreensão dos conteúdos programáticos a partir de sua aplicabilidade, desenvolvendo o senso crítico e criativo nas aulas de qualquer disciplina. De acordo com a BNCC, espera-se que os estudantes: "desenvolvam a capacidade de identificar oportunidades de utilização da matemática para resolver problemas, aplicando conceitos, procedimentos e resultados para obter soluções e interpretá-las segundo os contextos das situações" (BRASIL, 2017, p. 221).

Dentre esses procedimentos que podem ser utilizados em sala de aula, encontra-se a modelagem (matemática) como método de ensino - procedimentos envolvidos na feitura de um modelo. "Modelagem é o processo envolvido na elaboração de modelo de qualquer área do conhecimento" (BIEMBENGUT, 2014, p. 21), modelo que pode auxiliar as pessoas a compreender dados, informações, estimular novas ideias e prover de visão estruturada e global, que inclui relações abstratas de algum fenômeno, ente ou processo. Segundo Biembengut (2007), o modelo capacita a pessoa a observar e refletir sobre fenômenos complexos e, ainda, a comunicar as ideias a outras pessoas.

Nesse sentido, esta pesquisa tem como objetivo fazer uma análise comparativa entre os processos utilizados por uma modista em seus trabalhos profissionais, e os procedimentos de modelagem (matemática). E, a partir dos resultados, indicar caminhos passíveis de serem postos em prática nas aulas de Matemática.

\section{Pressupostos teóricos - Modelagem matemática}

De acordo com Biembungut (2014, p. 21):

Modelagem é o processo envolvido na elaboração de modelo [...]. Tratase de um processo de pesquisa. A essência deste processo emerge na mente de uma pessoa quando alguma dúvida genuína ou circunstância instigam-na a encontrar uma melhor forma para alcançar uma solução, 
descobrir um meio para compreender, solucionar, alterar, ou ainda, criar ou aprimorar algo. E em especial, quando a pessoa tem uma percepção que instiga sua inspiração.

Segundo Bassanezi, "trata-se de um processo dinâmico de busca de modelos adequados, que sirvam de protótipos de alguma entidade" (BASSANEZI, 2010, p. 45). Para o autor, um modelo matemático consiste em um conjunto de relações matemáticas e símbolos que, de alguma maneira, representam o objeto estudado. Ele afirma que esses modelos podem ser formulados conforme a natureza dos fenômenos ou situações analisadas e classificadas de acordo com o tipo de matemática utilizada.

De acordo com Bassanezi (2010), a modelagem (matemática) faz uma ligação entre as representações e o mundo. $\bigcirc$ autor a define como um processo dinâmico, utilizado para obter e validar modelos (matemáticos). Ele a considera uma forma de abstração e generalização com intuito de prever tendências. "A modelagem consiste, essencialmente, na arte de transformar situações da realidade em problemas matemáticos cujas soluções devem ser interpretadas na linguagem usual" (BASSANEZI, 2010, p. 24).

Assim como Bassanezi (2010), Biembengut (2014), Blum (2007), outros autores também afirmam que o processo de elaboração de modelos se dá por meio de muitas interações. Para iniciar um trabalho utilizando modelagem, é necessário dispor de uma situaçãoproblema que, para solução, não se disponha de dados suficientes para utilizar uma fórmula ou um caminho de solução. Assim, requer um levantamento de possíveis situações de estudo, as quais devem ser, preferencialmente, abrangentes para que se possam proporcionar questionamentos em várias direções.

Biembengut (2003, 2014, 2016), baseando-se em Kant (1980), George (1973) e Maturana e Varela (2003), denominou as três etapas de modelação (modelagem aplicada à educação), a saber: percepção e apreensão; compreensão e explicitação; e significação e expressão.

\section{- Percepção e apreensão}

Para Biembengut (2014), a percepção consiste em receber, identificar e classificar informações provenientes do meio. "A percepção implica na capacidade de captar eventos ou ideias, misturar, selecionar e relacionar com as que dispomos" (BIEMBENGUT, 2003, p. 6).

Para Madruga (2016), a percepção é a primeira fonte de conhecimento necessária para que se possa fazer uma descrição do meio, uma decodificação e representação. Posteriormente, a percepção tem relação com o pensamento, com a resolução de problemas e com os processos de decisão das pessoas. Trata-se de uma mediação necessária, mesmo que não suficiente, de toda objetivação real, afirma Biembengut (2003).

\section{- Compreensão e explicitação}

A compreensão é a etapa que une a percepção ao conhecimento. A partir da compreensão, um fato percebido adquire significado e, por consequência, torna-se conhecimento. Compreender é entender e expressar uma sensação de forma intuitiva. "Uma vez tendo sido sensibilizado com o fato apresentado, a mente procura explicar, relacionar com algo já conhecido e deduzir os fenômenos que daí derivam" (BIEMBENGUT, 2003, p. 8). A autora afirma que as informações e os estímulos são percebidos e podem ser compreendidos pela mente, que procura explicar ou explicitar, delineando símbolos ou fragmentos de símbolos.

- Significação e expressão 
Quando uma compreensão passa a ser significativa para a mente, pode-se dizer que se transformou em conhecimento, ou seja, ocorreu a aprendizagem, afirma Madruga (2016). Não são todas as percepções que geram aprendizagem, pois aprender significa mais do que armazenar informações, implica ter conhecimento. Conhecimento é o ato ou efeito de conhecer, capacidade da mente em significar ou modelar um evento ou informação e utilizá-lo quanto necessitar. Para Biembengut (2014), nesta etapa as percepções e/ou informações são compreendidas e explicadas em uma busca por traduzir ou representar estas percepções, e isso acontece com a utilização de símbolos e/ou modelos.

\section{Pressupostos metodológicos}

Este artigo apresenta um recorte de uma pesquisa maior no qual se aborda apenas um caso: a modista. A pesquisa em questão é de cunho qualitativo Bogdan e Biklen (1994) e Lincoln e Guba (1991). Para atingir o objetivo proposto adotou-se o mapeamento como princípio metodológico, (BIEMBENGUT, 2008). A fim de entender fatos e questões, servir-se do conhecimento produzido e reordenar setores deste conhecimento. De acordo com Biembengut (2008), o mapeamento visa possibilitar a formação de imagens da realidade, viabilizando assim o sentido de informações, captação de características e traços relevantes, representando-as e explicitando-as para que possam interessar, agir e imiscuir-se sobre a realidade. A pesquisa foi dividida em duas etapas: apreensão dos dados empíricos entrevistas por narrativas; e significação desses dados - análise do material coletado.

$\mathrm{Na}$ apreensão ocorreu a busca pela base teórica: modelagem (matemática). Na sequência, ocorreu o reconhecimento da pessoa (colaboradora da pesquisa: modista), bem como reconhecimento de seus trabalhos a partir de entrevista e observações. A entrevista foi realizada no ambiente profissional da participante da pesquisa. A partir daí, foram realizados os levantamentos de um conjunto de dados junto a essa colaboradora, fonte dessa pesquisa: modista. A profissional possui um atelier de moda em uma cidade na região metropolitana de Porto Alegre, Estado do Rio Grande do Sul, onde produz roupas exclusivas para clientes de diferentes localidades. Além disso, faz produções em larga escala para fábricas de roupas de diversos locais do Estado.

Dessa forma, a fonte desta pesquisa é oriunda principalmente da pessoa, desta, originou-se: 1) a entrevista, que perfizeram um total de aproximadamente três horas de gravação; 2) os dados coletados por meio de cerca de cinco visitas de observações no processo de criação; e 3) os documentos e produções por ela fornecidos.

A entrevista, por meio de narrativas, foi realizada no local de trabalho da entrevistada, e utilizadas para compreender a profissional em seu contexto. O uso de narrativas na pesquisa qualitativa fundamenta-se na convicção de que contar histórias é dar sentido a percursos e experiências. Segundo Larrosa, o "sentido do que somos depende da história que contamos e das que contamos a nós mesmos" (LARROSA, 1994, p.48).

As observações realizadas nos espaços de trabalho, criação e produção da profissional entrevistada foram um dos tipos de levantamento de dados utilizado nesta pesquisa. Biembengut (2008) afirma que as observações visam à obtenção de maior conhecimento, e precisa ser acurada suficientemente para que se possa ampliar e qualificar os elementos que estão sendo pesquisados. Dessa forma, durante as cinco visitas, foi possível verificar parte do processo de produção da entrevistada, contribuindo significativamente para o processo de análise dos dados. 
Os documentos analisados nesta pesquisa são provenientes de duas fontes: busca teórica realizada pela pesquisadora, e fornecidos pela pessoa colaboradora. Esses documentos basicamente consistem em: modelos, esboços e projetos. Segundo Biembengut (2008, p. 104), "a possibilidade de conhecer ou identificar as motivações das pessoas envolvidas na produção de um documento, [...] pode trazer resultados mais fidedignos e evitar conclusões equivocadas". Após dispor destes documentos, foi preciso identificá-los e relacioná-los com outros dados para obter argumentos para análise.

Na significação ocorreu a análise das narrativas, onde se apreciaram e avaliaram-se as narrativas da profissional colaboradora, dividindo-as conforme sua relevância, ou seja, categorizando e identificando os principais elementos, tanto constantes como variáveis. Biembengut (2008) afirma que explicitar as significações dos dados coletados necessita de percepção e compreensão dos mesmos, bem como de interpretação e avaliação do contexto e das pessoas envolvidas e, especialmente, de um julgamento do que é expressivo e grau de relevância. Para Biembengut (2008), a descrição e a compreensão são realizadas durante o percurso da pesquisa, e a interpretação e avaliação dos fenômenos ou entes de uma pesquisa depende do conhecimento do pesquisador sobre a teoria que sustenta o tema em questão, bem como da proposta de outro olhar sobre a teoria.

$\mathrm{Na}$ análise dos dados levantados, procurou-se compreender a articulação entre os fatores envolvidos, para que fosse possível identificar os efeitos que caracterizassem um fato que poderia ser considerado relevante para atingir o objetivo proposto, com a expectativa de possibilitar, desta forma, a interpretação e apreciação dos entes pesquisados, bem como o estabelecimento de questões-chave pertinentes para a análise. O foco desse estudo centrou-se no entendimento e na interpretação dos dados, a partir das narrativas da profissional, na inserção e na interação com seu ambiente sociocultural e natural.

\section{Resultados e discussão}

Para uma melhor compreensão e visualização das etapas de modelagem, a análise foi organizada nas três categorias que correspondem às fases propostas por Biembengut (2016):

\section{- Percepção e Apreensão}

No que se refere ao primeiro estágio de modelagem, conforme Biembengut (2016), percepção e apreensão, o intuito é identificar, entender o que deve ser feito no processo de modelação/criação. Nesta primeira categoria, considera-se a priori que para realização de um trabalho, em qualquer ramo profissional, há intenção, ou seja, é necessária uma identificação do que será feito: primeira ação da pessoa.

No caso da entrevistada, ela trabalha com o público procurando atender suas demandas. Seu trabalho consiste em criar modelos e/ou roupas para clientes (roupas exclusivas para mulheres, prioritariamente) e também em grandes quantidades (produção para empresas). Diz que percebe o que irá criar e/ou confeccionar por meio da uma solicitação de um(a) cliente, e a partir dali, verifica o que precisará fazer. Segundo suas narrativas, pode ser somente uma reprodução, no caso da cliente já vir com uma peça pronta. Ou, quando é produção por meio de modelo, neste caso a modista explica que é mais complicado, pois não é tudo que se adapta para todas as pessoas, depende das medidas de cada uma. 
Relatou que no momento da entrevista estava trabalhando também com produção para três lojas virtuais, criando e confeccionando as roupas mediante encomenda. Para saber exatamente o que um cliente quer e não correr o risco de criar e/ou confeccionar algo que não seja de seu agrado, a entrevistada diz que procura compreender o que lhe é solicitado, e faz isso ouvindo a cliente e procurando saber em quais circunstâncias pretende usar a peça por ela criada e confeccionada.

Afirma que, na maioria das vezes, quando as pessoas a procuram, já dispõem de um modelo pronto, uma ideia: "Quase sempre quando as pessoas vêm, elas já vêm com um modelo determinado". A profissional cria modelos novos e também produz por meio de peças já prontas o que, segundo ela, facilita o trabalho: "Quando é uma roupa que já é delas, é só fazer igual e pronto".

Em outras ocasiões, os clientes apresentam um desenho, um modelo criado por outra pessoa, ou até mesmo recortes de revistas ou jornais, o que, por vezes, dificulta o trabalho da profissional: "quando elas vêm com desenho, quase todas as vezes eu tenho que mudar porque nem sempre o que está no papel é aquilo que a pessoa desenha na cabeça dela". Esta afirmação significa que, ao visualizar um modelo em outra pessoa ou em um desenho, não há obrigatoriedade que o mesmo mostre-se bem para quem o deseja usar: "corpo é que nem rosto, cada um tem um formato diferente, nem sempre o que fica bom pra um, fica bom pra outro". Nestes casos, a modista comenta que há necessidades de adequações individuais.

Reforçando a afirmação, diz que: "a pessoa idealiza uma roupa e pensa: Nossa! Vai ficar igual o que está no papel! E nem sempre é assim". Segundo ela, nestas situações, procura criar a peça com a maior aproximação possível da intenção do cliente, alertando e explicando os ajustes que são necessários realizar para que o resultado seja o mais fiel possível à ideia da pessoa.

Sobre seu outro viés de trabalho - empresas -, afirma que estes, sim, são modelos de sua autoria. A empresa a informa sobre a ideia que pretende vender, e, a partir destas indicações, a profissional cria os modelos e posteriormente as roupas: "os modelos são todos criados por mim, eles me passam na verdade uma ideia do que eles querem".

A entrevistada também comenta que procura saber para que ocasião a pessoa pretende usar a roupa confeccionada, ou seja, averígua a intenção da pessoa. Segundo ela, esta informação facilita o trabalho: "também depende para que é a roupa, depende para que ocasião é a roupa". E continua:"se vai ser para uma festa, se vai ser para usar a noite, depende muito o que a pessoa está buscando". Essa ideia de saber o que se está buscando pode ser comparada ao estágio de escolha do tema na modelagem (matemática) em que há uma percepção do que será estudado posteriormente (BIEMBENGUT, 2003, 2014).

Percebeu-se que o trabalho da modista parte de uma ideia vinda da(s) cliente(s), e essa ideia, por vezes, necessita de uma adequação por parte da profissional visando um melhor resultado, seja no momento da conversa inicial, para reformulação da ideia, seja na elaboração do modelo (desenho), seja no momento da produção da peça propriamente dita. Todavia, os modelos e produções sempre partem da intenção da(s) cliente(s). Segundo Bassanezi (2015, p. 16), "o início de uma modelagem se faz com a escolha de temas".

A entrevistada comenta que, em virtude de não ter formação específica em moda, o que aprendeu foi com a experiência adquirida no decorrer dos anos, e também por meio de muitas 'pesquisas': "sempre pesquisei muito, sempre andei muito nas lojas, tirei muita foto de vitrine [...]. Pegava um modelo que às vezes... eu não tinha... porque como eu não 
tenho curso nenhum, tinha coisa que eu não sabia... onde é que era o começo, o meio e o fim. Eu pegava a peça e desmontava toda a peça e fazia de novo, muitas peças eu fiz assim... até aprender". Relatou que até mesmo atualmente, quando recebe alguma solicitação diferenciada, faz buscas, 'pesquisas', para que seu trabalho seja o mais perfeito possivel.

Por meio de suas narrativas, percebeu-se que houve inicialmente uma apreensão do que deve ser feito para cada cliente, (BIEMBENGUT, 2014). A partir daí, ao se apropriar de informações que thes possam ser úteis nas etapas seguintes, busca mais subsídios, procurando saber mais sobre o tema ou problema, na tentativa de que novas ideias emerjam - familiarização com o assunto (BASSANEZI, 2010), para que possam dispor de um referencial teórico e/ou dados que possibilitem que suas criações sejam as mais adequadas possíveis.

\section{- Compreensão e Explicitação}

A entrevistada afirma que após as conversas iniciais com as clientes, são elaborados (ou trazidos por elas) esboços - modelos - para que a pessoa visualize como ficará a roupa, e também para facilitar o trabalho da modista. Após a elaboração desse modelo, há uma busca por materiais que melhor se adaptem ao que a cliente procura: "depois que eu faço o desenho, que eu vou ver [...] o material que vai se adequar àquele modelo". Explica a importância de se adequar o material ao modelo: "às vezes elas olham um vestido de cetim, mas elas querem fazer de chifon. É completamente diferente, não dá! Daí para cada modelo tu tem um tipo de material que é adequado".

São esclarecedoras as narrativas que dizem respeito ao processo de produção, trabalho que a modista também executa. Ela salienta ser bem diferente dos modelos exclusivos. A produção para empresas necessita de um 'piloto', a partir do qual se começa a fazer a grade, como explica a entrevistada: "eles me passam uma ideia, e eu tenho que praticamente entrar dentro da mente deles para descobrir o que eles querem. Daí em cima disso a gente faz um piloto, eles aprovam o piloto e aí a gente começa a fazer a grade. [...] Esse piloto eu faço modelo, desenho, daí eu faço no papel, aí eu faço todas as medidas que têm que ser usadas nos vestuários, porque a gente tem uma tabela de medida. Então, antes de fazer o molde, tu tem que enquadrar ele no tamanho P, M, G e fazer toda a grade de modelagem".

A entrevistada explica com riqueza de detalhes como é produzida esta 'grade de modelagem': "A grade de modelagem é feita a partir da peça, eles pensam numa peça, aí eu vou pegar ela e vou desenhar num papel, que não tem tamanho, só para eles poderem visualizar, dali eu vou pegar e vou usar as medidas que são medidas padrão. Na verdade, a medida padrão para poder fazer um modelo tem que usar quatro medidas: ombro, braço, busto, cintura. Então, essa é a medida que tem que usar para tornar a peça padrão". Essa 'grade de modelagem' produzida pela entrevistada é o que Bassanezi (2010) chama de modelo objeto. Um modelo objeto é a "representação de um objeto ou fato concreto; suas características predominantes são a estabilidade e a homogeneidade das variáveis" (BASSANEZI, 2010, p.19-20).

Após esta etapa, passa-se então à construção propriamente dita do produto que será apresentado pela modista, onde há uma explicitação, (BIEMBENGUT, 2016), ou resolução do problema, (BASSANEZI, 2010). Esta etapa de significação confunde-se muito com a etapa de compreensão, pois ora se está produzindo esboços, ora se está criando o produto, e ora volta-se aos esboços em uma espécie de processo cíclico, (BLUM, 2007). Nesse processo já 
há uma avaliação preliminar. Considera-se que a avaliação permeia todo processo, e não ocorre somente na fase final.

Os trabalhos da entrevistada são divididos em dois formatos: a confecção de modelos exclusivos e a produção. Sobre o processo de produção, a modista afirma que é necessário o modelo (grade), e comenta sobre a diferença de produzir em grande quantidade e uma roupa exclusiva: "a grade a gente faz e fica com ela guardada, não é como fazer uma roupa sob medida, que tu tem que medir todas as partes da pessoa, fazer uma prova de ajuste, e na verdade é o que eles dizem que é a roupa costurada no corpo. Que daí tu vai fazer, especificamente para aquela pessoa, é diferente do que tu fazer produção".

Nesse processo, após a criação da grade conforme mencionado anteriormente, ela explica seus procedimentos: "de uma peça, na verdade a gente sempre usa a peça média. A primeira peça sempre que é feita é a média. Aí da média diminui para $P$ e da média aumenta para G. A diferença de medida de uma peça para outra é de um centímetro e meio a dois centímetros no máximo, tem que ter de diferença de numeração, não pode ter mais que isso. A partir desses vai reproduzindo". E continua ao falar sobre o processo de produção: "porque daí tu vai fazer, 50 peças $P$, elas vão sair exatamente as 50 peças do mesmo tamanho".

Biembengut e Hein (2011) trazem em seu livro sobre modelagem matemática no ensino uma referência ao trabalho da modista:

Uma modista é solicitada para fazer uma roupa a uma cliente com estatura mediana, idade superior aos quarenta anos e peso um pouco acima dos padrões. A cliente espera que a roupa a deixe mais magra, mais alta, mais jovem, elegante e bonita. Nesse caso, a modista precisará pensar no tipo e na cor do tecido e no modelo de tal forma 'criando a ilusão' em sua cliente e nos outros dessa imagem desejada. A modista, além de conhecimento geométrico e medidas, tecidos e adereços, precisará ter uma dose de criatividade, intuição para fazer ressaltar os atrativos de sua cliente. (BIEMBENGUT; HEIN, 2011, p.17).

Em suas confecções de grande escala - produção, ela cria um modelo e a partir dele produz várias roupas iguais. Conforme as narrativas, esta fase de criação é composta pelas ações de produção de esboços e de produtos (modelos) que os entrevistados irão apresentar para apreciação das pessoas, sejam clientes ou o público de uma maneira geral. Pode-se dizer que nesta etapa houve a formulação e resolução do problema, etapa da modelagem (matemática) proposta por Biembengut (2007) e Bassanezi (2010). Conforme Biembengut (2007), esta etapa, especialmente importante na modelagem (matemática), consiste na classificação das informações coletadas na fase anterior, na identificação dos fatos envolvidos, na formulação do modelo.

A formulação do problema baseia-se na elaboração dos primeiros esboços, enquanto que a execução é a resolução do problema (modelo), (BASSANEZI, 2010). No dizeres de Biembengut (2000, p. 4), "uma vez modelada, resolve a situação-problema a partir do modelo, realiza-se uma aplicação e interpreta-se a solução". Para Biembengut (2016) há, nesta fase, uma compreensão e explicitação do processo de modelar.

\section{- Significação e Expressão}

A criação da profissional entrevistada, ou seja, seus modelos são modificados a partir de novas percepções e compreensões, isto é, a partir de seus esboços e da avaliação/adequação prévia tanto de sua parte como da parte dos clientes e, após esta 
significação, são expressos por meio da linguagem, na maioria das vezes simbólica. A partir daí, ocorre a interpretação da solução e validação, e avaliação do modelo, (BASSANEZI, 2010). Quando há a expressão do que foi criado, quando o modelo é validado e avaliado por todas as pessoas, (BIEMBENGUT, 2014). Se o produto for satisfatório, esta etapa é considerada a final. Se for insatisfatório, retorna-se à(s) etapa(s) anterior(es), conforme necessidade.

Uma vez traduzidos e representados os dados por meio de um modelo é preciso saber se faz sentido e se é válido. Além disso, é preciso avaliar em que medida o modelo contribui para a solução da situação-problema e, por fim, verificar, sistematicamente, a valia do modelo na produção ou na transformação de algo: objeto, técnica, tecnologia, teoria, (BIEMBENGUT, 2007).

Biembengut (2000) salienta que, para validar o modelo é necessário fazer uma avaliação que verifique em que nível se aproxima da situação-problema representada. É preciso fazer a interpretação do modelo, juntamente com uma análise das implicações da solução, e verificar sua "adequabilidade, retornando à situação-problema investigada e avaliando quão significativa e relevante é a solução - validação" (BIEMBENGUT, 2000, p.15). Dessa forma, a etapa da expressão do produto é demarcada pela interpretação, validação e avaliação do modelo, ou seja, da roupa produzida pela modista.

A entrevistada salienta que após a confecção das peças, são realizadas avaliações, feitas pela própria modista e também pela cliente, no que se refere ao gosto da pessoa que irá usar a peça. No caso da criação de roupas exclusivas, sobre sua avaliação a modista afirma que ocorre: "no vestir, no experimentar tu via que às vezes faltava cava, ou não fechava com aquilo que eu imaginava que era. [...] Até no tu montar as peças tu já vê... porque na verdade, é tolerável uma diferença de... se tu vai montar uma peça na outra, de no máximo um centímetro e meio de diferença pode dar. Um pouquinho maior, se passar disso é porque tem alguma peça ali que está errada.[...] Na hora da montagem a gente já vê. E quando experimenta já constata que realmente, que ficou com problema".

A modista menciona sobre a criação de roupas exclusivas e da necessidade de avaliação durante o processo: "tem muitas roupas e muitos materiais que tu tem que realmente, quase costurar a roupa no corpo. Tem que experimentar, daí tu tem que riscar a roupa com a pessoa vestida no corpo, para ti poder chegar... porque tem pessoas que têm as medidas muito [...] diferentes. [...] Roupa sob medida é realmente roupa feita só para aquela pessoa".

A entrevistada afirma que normalmente procura fazer os ajustes necessários no decorrer da confecção, mas, se houver necessidade de mudanças depois da peça pronta, elas são realizadas. A modista diz que muitas vezes percebe que algo não está de acordo com o esperado e procura avisar a cliente. Diz que: "pelo molde do corpo [...] eu tinha certeza! Eu disse para elas que não ia dar e elas: -'Não, mas eu quero que faça assim!' - E quando elas colocaram... não deu". E continua sua narrativa: "é um risco que tu corre, tu falar e a pessoa aceitar ou não. Mas se experimentar e achar que precisa de mudança eu faço. Na verdade eu já prefiro, antes de fazer já [...] dizer o que eu acho de como vai ficar. Porque quando uma pessoa manda fazer uma roupa ela cria expectativa".

Sobre as expectativas das clientes, comenta: "então eu já mudo nas partes que eu acho que tem que mudar para pessoa quando colocar se sentir satisfeita com o que ela está usando. Porque é frustrante tanto para pessoa quanto para mim que faço, olhar na cara da 
pessoa e ver que não gostou do 'negócio'. Então eu já sempre procuro antes de acontecer, já evitar".

No caso do processo de produção para lojas, salienta a importância de seguir os padrões determinados pelo Inmetro $^{2}$, sob pena de ser multada caso as medidas não estejam de acordo. Dessa forma, também há uma avaliação externa de um setor competente: "produção tu tem que fazer toda uma grade, que tem que ser sempre padrão com as outras empresas, ela não pode fugir muito, o máximo que uma roupa pode ter de diferença de uma empresa para outra, que é permitido pelo Inmetro é de um centímetro, um centímetro e meio. Se eles pegarem uma peça média de uma empresa e uma peça média da outra empresa e tiver com mais de dois centímetros de diferença... porque a gente tem dos moldes que são originais de tamanho, a gente é multada. Então tem que tomar esse cuidado".

Explica sobre o processo de avaliação realizado pelo órgão responsável: "tu não pode simplesmente pegar e largar no mercado, não tu tem que todo o cuidado de medida, de tamanho. No Inmetro tem um órgão específico que cuida do vestuário, que verifica isso, [...] então existe essa avaliação".

A avaliação é uma constante, não somente nesta etapa final, como também perpassando todo o processo. Em vários momentos, a entrevistada mencionara o fato de 'avaliar' e 'reavaliar', tanto por parte da própria profissional, como por parte das outras pessoas envolvidas no processo. Nesta etapa há também uma 'apresentação do produto', ou seja, uma validação e avaliação, conforme Bassanezi (2010), ou ainda uma significação e expressão do que foi criado para que as outras pessoas possam apreciá-lo e validá-lo, (BIEMBENGUT, 2016).

Assim, análise das narrativas da modista possibilitou à autora desta pesquisa identificar as três fases do processo de modelagem (matemática) utilizadas para solucionar ou compreender uma situação-problema ou um fenômeno. Segundo Biembengut (2003), as pessoas em seu trabalho de criação recebem vários tipos de informação de fontes diversas que, uma vez selecionadas e reorganizadas, podem gerar novos conhecimentos frente a novas necessidades impostas pelo meio, sejam econômicas, sociais, históricas ou culturais.

\section{Considerações finais}

Este artigo teve como objetivo fazer uma análise comparativa entre os processos utilizados por uma modista em seus trabalhos profissionais, e os procedimentos de modelagem (matemática). De acordo com a análise, percebeu-se que os processos desta pessoa criativa é similar aos procedimentos de modelagem (matemática) nas concepções de Bassanezi (2010) e Biembengut (2007, 2014, 2016).

Madruga (2016) afirma que as pessoas, durante seus processos de criação, utilizam etapas similares às de modelagem prescritas por Bassanezi (2010, 2015), Biembengut (2003, 2007, 2014, 2016), Blum (2007), entre outros. De acordo com Bassanezi (2015), a utilização da modelagem no processo de ensino e de aprendizagem propicia a oportunidade de

\footnotetext{
${ }^{2}$ Instituto Nacional de Metrologia, Qualidade e Tecnologia.
} 
exercer a criatividade, não apenas em relação às aplicações das habilidades matemáticas, mas, principalmente, na formulação de problemas originais.

\begin{abstract}
Pensando na modelagem e suas potencialidades no contexto da escola, é necessário que os professores, desenvolvam um trabalho de forma diferenciada, visando a resolução de problemas do cotidiano e que sejam relevantes para o grupo de estudantes, considerando suas realidades. (MADRUGA, 2017a, p. 102).
\end{abstract}

Cabe ao professor utilizar estratégias metodológicas que estimulem o desenvolvimento da aprendizagem do estudante. "É fundamental abrir espaço, dentro do contexto escolar, para que diferentes formas de expressão e aprendizagem sejam respeitadas e valorizadas por seu significado no processo de assimilação cultural e de construção do indivíduo na sociedade" (AROUCA, 2012, p.19).

Pode-se dizer que a modelagem, de uma maneira geral, é eficaz em muitos casos, inclusive em razão de as pessoas utilizarem seus princípios mesmo sem terem tal conhecimento. Nos diversos ramos profissionais, conforme afirma Madruga (2016), as pessoas utilizaram a modelagem para resolver seus problemas e externalizar suas criações. A modelagem, utilizada não somente na disciplina de Matemática, como também em qualquer outro componente curricular, pode auxiliar no processo de ensino e aprendizagem, bem como desenvolver o senso criativo nos estudantes e, dependendo da temática, valorizar a cultura e o entorno onde vivem, (MADRUGA, 2016).

O estudo de distintos processos criativos, por exemplo, permite ao estudante inteirar-se de conceitos de diferentes áreas do conhecimento e, ao mesmo tempo, conhecer e valorar a cultura de cada grupo social.

Nesse sentido, Madruga (2013) apresentou um relato de prática que vem ao encontro destas afirmações. Trabalhando com $6^{\circ}$ ano do Ensino Fundamental, aplicou uma proposta de modelagem (matemática), baseada nos princípios de Bassanezi (2010) e Biembengut (2003, 2007), na qual abordava o trabalho justamente de uma modista.

Com a ideia da temática - escolhida pelos estudantes, pois muitos deles tinham familiares que trabalhavam nesta profissão - começaram a desenvolver um projeto que levou aproximadamente dois meses, onde: 1) Após a escolha da temática, familiarizaram-se com o assunto por meio de vídeos, palestra com profissional da moda e entrevista com modistas que faziam parte de seu cotidiano; 2) Desenharam um esboço de uma roupa que iriam produzir (alguns fizeram roupa de boneca, outros para cachorro); após o primeiro esboço - livre - produziram outro desenho com maior rigor matemático, e por fim, confeccionaram a roupa idealizada; 3) Analisaram os desenhos e a roupa e comunicaram os resultados por meio de um desfile de moda realizado na escola.

Cabe salientar que durante a segunda fase (momento de criação dos desenhos e das roupas propriamente ditas - compreensão e explicitação) emergiram muitos dos conteúdos matemáticos que deveriam ser desenvolvidos naquele ano, por exemplo: frações e operações, números decimais e operações, unidades de medidas, além de noções de escala e porcentagem. Estes conteúdos foram trabalhados em aula no decorrer desta segunda etapa.

Partindo da ideia que os profissionais, nos mais diferentes ramos utilizam-se da modelagem mesmo que implicitamente em seus fazeres, conforme afirma Madruga (2016), parece-nos claro que esses procedimentos também podem ser eficazes na escola para ensino e aprendizagem de diferentes conteúdos não somente matemáticos. Nesse sentido: 
"A modelagem pode ser utilizada em qualquer área do conhecimento. Especialmente, no entendimento de algum fenômeno, na solução de alguma situação-problema, ou ainda, na criação ou na produção de algo" (MADRUGA, 2017b, p.59).

\section{Referências}

AROUCA, Carlos A. C. Arte na escola: como estimular um olhar curioso e investigativo nos alunos dos anos finais do ensino fundamental. São Paulo: Editora Anzol, 2012.

BASSANEZI, R. Ensino-aprendizagem com modelagem matemática. 3. ed. 2a reimpressão São Paulo: Contexto, 2010.

BASSANEZI, R. Modelagem matemática: teoria e prática. São Paulo: Contexto, 2015.

BIEMBENGUT, M. S. Mapeamento na pesquisa educacional. Rio de Janeiro: Editora Ciência Moderna, 2008.

BIEMBENGUT, M. S. Modelagem e Processo Cognitivo. In: Conferência Nacional de Modelagem e Educação Matemática - CNMEM, 3, 2003. Piracicaba. Anais. Piracicaba, 2003.

BIEMBENGUT, M.S. Modelagem na Educação Matemática e na Ciência. São Paulo: Editora Livraria da Física, 2016.

BIEMBENGUT, M. S. Modelagem matemática e etnomatemática: pontos (in)comuns. In: Congresso Nacional de Etnomatemática, 1, 2000. São Paulo. Anais. São Paulo, 2000.

BIEMBENGUT, M. S. Modelagem matemática e implicações no ensino e aprendizagem de matemática. 3. ed. Blumenau: Edifurb, 2007.

BIEMBENGUT, M. S. Modelagem matemática no ensino fundamental. Blumenau: Editora da FURB, 2014.

BIEMBENGUT, M.S. HEIN, N. Modelagem Matemática no Ensino. $5^{a}$ ed. $2^{a}$ reimpressão. São Paulo: Contexto, 2011.

BOGDAN, R.; BIKLEN. Investigação qualitativa em educação. Porto, Portugal: Editora Porto, 1994.

BLUM, W. et al. Modelling and Applications in Mathematics Education. New York: Springer, 2007.

BRASIL. Ministério da Educação, Secretaria de Educação Média e Tecnológica. Parâmetros Curriculares Nacionais - Ensino Médio. Brasília: 1999.

BRASIL. Base Nacional Comum Curricular - BNCC. Disponível em: <http://basenacionalcomum.mec.gov.br/images/BNCC_publicacao.pdf>. Acesso: 3 jun.2017.

BRASIL. Ministério da Educação. Secretaria de Educação Básica. Diretrizes Curriculares Nacionais Gerais da Educação Básica. Brasília: 2013.

BRASIL. LDB: Lei de Diretrizes e Bases da Educação Nacional. Lei no 9.394, de 20 de dezembro de 1996, que estabelece as diretrizes e bases da educação nacional. 9. ed. Brasília: Câmara dos Deputados, Edições Câmara, 2014. 
BRASIL. Ministério da Educação, Secretaria de Educação Média e Tecnológica. Parâmetros Curriculares Nacionais - Ensino Médio. Brasília: 1999.

GEORGE, F. Modelos de Pensamentos. Trad. Mário Guerreiro. Petrópolis: Vozes, 1973.

KANT, I. Primeira Introdução à Crítica do Juízo. Trad. de Torres Filho, R. R. São Paulo: Abril Cultural, 1980.

LARROSA, J. Tecnologias do eu e educação. In: SILVA, T. T. O sujeito da educação. Petrópolis: Vozes, 1994, p.35-86.

LINCOLN, Y.; GUBA, E. Naturalistic inquiry. New York: Sage, 1991.

MADRUGA, Z. E. F. A modelagem (matemática) implícita nos fazeres de diferentes pesquisadores. Boletim do LABEM, v. 8, n. 14, jan/jun. de 2017 a.

MADRUGA, Z. E. F. A perspectiva 'etnomodelagem' presente nos fazeres de um coreógrafo. Revista Educação, Ciência e Cultura, Canoas, v. 22, n. 2, p. 57-69, jul. 2017b.

MADRUGA, Z. E. F. Pessoas que criam: projeto interdisciplinar utilizando princípios de modelagem matemática na Educação Básica. In: Congreso Iberoamericano de Educación Matemática, 7, 2013: Montevideo. Anais. Montevideo, 2013.

MADRUGA, Z. E. F. Processos criativos em diferentes contextos: possibilidades de aprender com modelagem. 2016. Porto Alegre. Tese (Doutorado em Educação em Ciências e Matemática) Pontifícia Universidade Católica do Rio Grande do Sul, Porto Alegre, 2016.

MATURANA, H. R.; VARELA, F. J. A árvore do conhecimento. Trad. Jonas Pereira dos Santos. Campinas: Editora Psy II, 2003. 